\title{
A new perspective towards failure of gamma nail systems
}

\author{
ŞERBAN DRAGOSLOVEANU ${ }^{1,2}$, CHRISTIANA D.M. DRAGOSLOVEANU ${ }^{3}$, HORIA T. STANCA ${ }^{3}$, \\ DRAGOŞ C. COTOR ${ }^{3}$, CĂLIN I. DRAGOSLOVEANU ${ }^{3}$ and CRISTIAN I. STOICA ${ }^{1,2}$ \\ ${ }^{1}$ Department of Orthopedics, 'Carol Davila' University of Medicine and Pharmacy, 050474 Bucharest; \\ ${ }^{2}$ Department of Orthopedic Surgery, 'Foişor' Orthopedics-Traumatology and Osteoarticular TB Hospital, 030167 Bucharest; \\ ${ }^{3}$ Department of Ophthalmology, 'Carol Davila' University of Medicine and Pharmacy, 050474 Bucharest, Romania
}

Received September 4, 2020; Accepted October 5, 2020

DOI: $10.3892 /$ etm.2020.9346

\begin{abstract}
Uncommon causes of nail failures and surgical reinterventions were determined. The study included 23 osteoporotic patients, 13 of whom followed a fast recovery program with early walking (FWB group). The other 10 patients were not allowed full weight bearing until 6 weeks (NFWB group). The T-score was determined before surgery for all cases. A case with a nail breakage after a failed DCS implant fixed in another clinic was also analyzed. The nail was revised and the broken implant underwent a metallurgic and microscopic examination. The average T-score was 2.5 for the patients that followed the fast recovery program and 2.7 for the patients from non-full weight bearing. Four patients, 1 from the NFWB group and 3 from FWB group, presented a screw cut-out. It was found that the errors of the guiding instruments may create dents, scratches or micro-fractures on the titanium coating that lead to an early implant failure. Imperfect reduction leads to incorrect implant placement and a high incidence of failure. Damaging the titanium protective coating, in a low force, high cycles scenario can cause structural failure. Delays in fracture healing and material fatigue are the most common causes of nail failure and can lead to catastrophic complications.
\end{abstract}

\section{Introduction}

Trochanteric fractures occurring in adults represent a challenging pathology from an orthopedic point of view. Most of these patients are old, with associated comorbidities and sometimes with fractures resulting from high intensity trauma. Mechanical complications are in general less frequent than

Correspondence to: Dr Christiana D.M. Dragosloveanu, Department of Ophthalmology, 'Carol Davila' University of Medicine and Pharmacy, Bulevardul Eroii Sanitari 8, Bucharest 050474, Romania

E-mail: christianacelea@gmail.com

Key words: trochanteric fractures, internal fixation, gamma nail system, nail failure, titanium fatigue, displaced implant systemic ones. Some of the truly elderly patients or the ones with various lytic tumors present at the emergency room with pertrochanteric fractures resulting from low-level trauma. Most complications are due to severe osteoporosis or malposition of the implant. Although rheumatological research is still in progress, osteoporosis treatment has not yet succeeded to reduce the complications of trochanteric fractures, which are increasing in older patient groups (1). The poor compliance of patients undergoing rheumatological treatments may be one of the causes for pertrochanteric fractures $(2,3)$. Increasing life expectancy in Romania (75.31 years, data from TheWorldBank. com) also may be a factor for this increasing pathology.

Elderly patients, unless operated rapidly, may lose the will to resume walking; therefore, a conservative, non-surgical treatment is not desirable. Studies in literature showed a higher mortality rate and poor functional results after conservative approach.

The most frequent types of surgical treatment used in this pathology are those of reduction and osteosynthesis with intramedullary nails, DHS, as extramedullary osteosynthesis $(4,5)$.

Our method of choice in treating this pathology is the reduction and internal fixation with a titanium made gamma-nail system. Due to some complications encountered during our practice, we decided to make an ample review of literature, an adequate analysis of our complicated cases and a mechanical test of the implant we used, in order to identify the factor that influences the breakage point.

Trochanteric fractures are fractures that affect the proximal $1 / 3$ of the femur, starting from the base of the femoral neck up to $5 \mathrm{~cm}$ below the small trochanter (6).

Although there are several classifications used for this anatomical region based on various factors, the most common are those based on the fracture path $(7,8)$ and the degree of comminution. In this study, we used the Evans Classification, which is divided into five types, starting with the first one (non-displaced with 2 fragments) and ending with the $\mathrm{V}$ degree, where comminution is high (Fig. 1) (9). The classifications of pertrochanteric fractures, like all classifications, have their limitations regarding reproducibility. The main challenge is to achieve a satisfactory reduction, before surgery, under C-Arm X-rays.

An increasing number of cases of pertrochanteric fractures affecting the elderly were reported in hospitals across Romania. Pertrochanteric fractures are associated with increased bone 
fragility, with falls from the same level or with psychiatric or heart problems, in some patients (10).

The diagnosis of trochanteric fracture is made clinically, the affected limb being shortened and in adduction plus external rotation. Although the diagnosis is clinical in most cases, type 1 trochanteric fractures in the Evans classification do not display an external rotation and the diagnosis cannot be complete without an X-ray in the anteroposterior and lateral incidence, since imaging is crucial in determining the classification (Fig. 2). The X-ray exposure can be completed with a CT in cases where a fracture is suspected on pathological background.

Trochanteric fractures are common in patients over 70 years of age who have various comorbidities, among which malnutrition and severe osteoporosis (11).

In patients aged 70 years, the immediate postoperative complications are represented by the loss of the ability to walk, as well as the failure to cope psychiatrically and emotionally. Rehabilitation has a crucial role and it is sometimes hard to exert.

The treatment of this pathology must be quick, with limited blood loss and a fast recovery of walking. Theoretically, the patient should be encouraged to walk immediately after surgery, even at the risk of full weight bearing on the fractured limb. Regardless of the chosen treatment, the complications that may occur pre- or postoperatively, the treatment of pain, the prevention of pulmonary thromboembolism and the maintenance of an adequate musculature must be taken into account.

From the analysis of cases with failed mechanical device stability, we aimed to identify the causes that lead to reintervention and sometimes death from a scientific point of view.

\section{Materials and methods}

During surgery, we follow the international guidelines and the manufacturer's implanting technique. In all cases, we struggle to achieve a close-to-perfect preoperative fracture reduction. The positioning of the patient is important. The orthopedic table is used and the fracture is reduced, a maneuver that later helps us when implanting the nail in the ideal position. The maneuver of reduction on the orthopedic table is performed under radiological control.

Small incisions are performed and the nail is implanted intramedullary and stabilized. X-rays are used on all patients to verify the correct position. The ideal position for the lag screw is inferior and posterior in the femoral head (12). For all our patients, Gamma nail implants made of titanium were used, from the same manufacturer. The implant had cervical-diaphyseal angle of $125^{\circ}$, a distal diameter of $10 \mathrm{~mm}$, a U-lag screw, and a distal static screw. Since we encountered one case with a broken implant, we decided to analyze in laboratory conditions in order to identify what are the factors that influenced its durability. Patients with severe osteoporosis were included in this study to verify the efficiency of fast rehabilitation program with immediate full weight bearing. Patients with non-consolidation were included and also one patient with implant failure, due to septic complications.

Stress testing on the implant was done in a different center. Extremely interesting findings led us to a close check on the

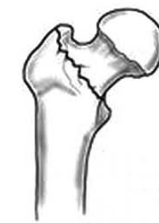

।

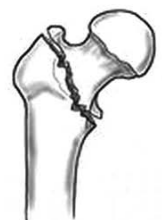

II

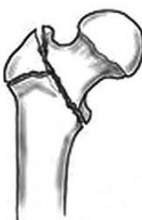

III

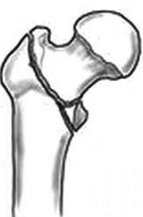

IV

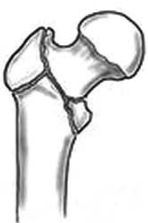

$\mathrm{V}$
Figure 1. Evans Classification. Type I, undisplaced 2 parts. Type II, displaced 2 parts fracture. Type III, displaced 3 parts fracture with greater trochanteric comminution. Type IV, displaced 3 parts fracture with postero-medial comminution. Type V, displaced 4 parts fracture involving both trochanters.

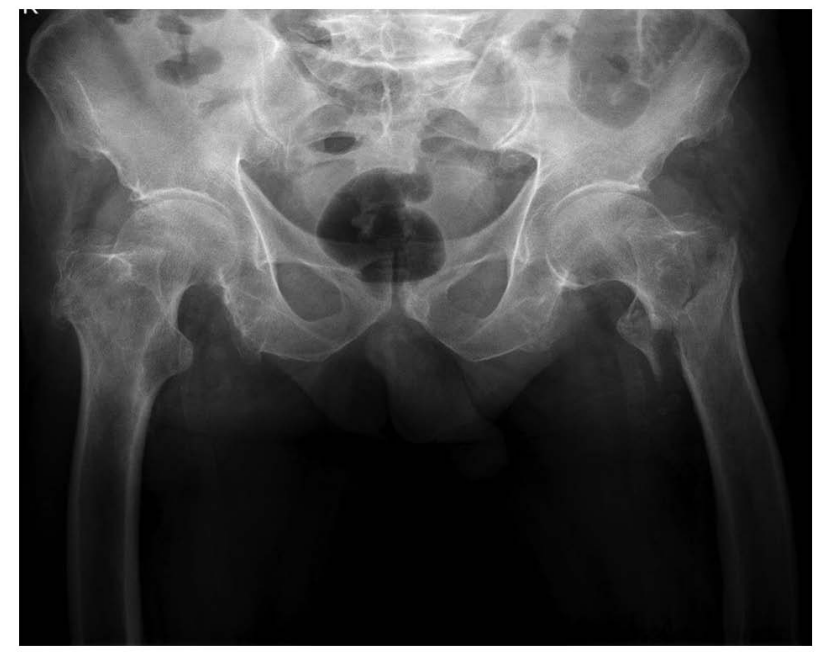

Figure 2. Rx image with left pertrochanteric fracture.

nail's surgical tray for accuracy and measurement tolerances. Results will be discussed later in the report.

The study was approved by the Ethics Committee of 'Foişor' Orthopedics-Traumatology and Osteoarticular TB Hospital (Bucharest, Romania). All patients provided a signed informed consent.

Twenty-three patients with previous osteoporosis were included in the study, 10 were not allowed for full weight bearing until 6 weeks after surgery, and 12 were following a fast recovery program, with early walking. Osteoporosis was diagnosed for all before surgery, and all the patients were under treatment for this pathology. T-score was recorded for each patient.

One patient, operated in another clinic, was admitted in our hospital, in the emergency room, with severe sepsis. A failed and displaced implant was identified on the X-rays. The CT scan was necessary in order to examine any secondary septic determinations.

One patient operated in another emergency clinic with a DCS system for a right hip fracture needed second surgery. The gamma nail that we used failed after one year. A full set of blood tests were performed for all patients.

\section{Results}

Titanium and titanium alloys, which have been used widely as biomedical implant materials since the 1970s, possess the 


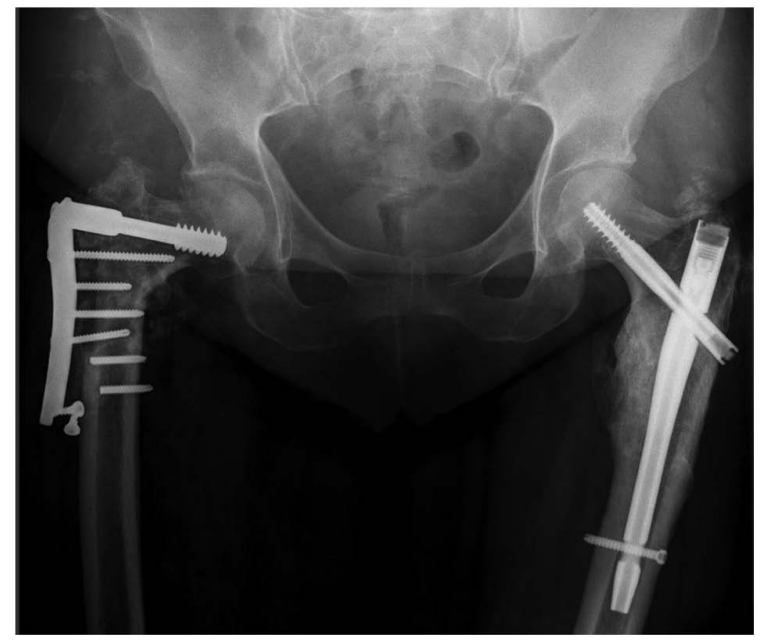

Figure 3. Before right hip surgery.

desired properties or biomedical applications, such as excellent biocompatibility, good corrosion resistance, and high ratio strength (13-15). In this study, we only used the same brand of titanium nails.

Twenty-three patients with osteoporosis were included in the study. Follow-up was at 6 months, until fracture healing. The average T-score was 2.6 for the whole group. Randomly assigned, by means of the operating surgeon, 10 patients were not allowed for full weight bearing rehabilitation (NFWB group). Their average T-score was 2.7. The other 13 patients had an average T-score of 2.5 (FWB group). None of these patients had major comorbidities. All the patients were over 70 years old. No septic complications were recorded. The body mass index (BMI) was between 26-31. No significant influence was identified; therefore, the topic was not addressed.

The average $\mathrm{T}$-score was not statistically significant ( $P>0.01)$, small differences in the T-score did not change the postoperative results. The only difference in the rehabilitation program, between the two groups, was the full weight bearing indication. NFWB group had 1 case of screw cut-out that needed reintervention. Lag screw was malpositioned. Weight bearing was possible, but with moderate pain. The patient had a reintervention, with total hip arthroplasty with revision stem. $10 \%$ of this group had cut-out complications.

In the FWB group, 3 patients had cut-out screws, with gradual moderate pain. One patient had a small screw displacement, but without cut-out. Twenty-three percent of these patients encountered mechanical complications during the first 3 months. Statistically, early weight bearing does not benefit from the postoperative results, increasing the number of osteoporotic patients with mechanical failures $(\mathrm{P}<0.01)$. Taking into consideration that one of these cases had the lag screw positioned in a non ideal location, statistically, it seems that faster rehabilitation does not increase the chance of screw cut-out with a big percent, but in fact, the screw position is the most important.

The second aspect of this study is represented by a patient with bilateral hip fractures ( 2 years distance between fractures), operated in another emergency clinic with a DCS system. We changed the implant with an intramedullary nail. The right hip is of interest for this research. We applied the

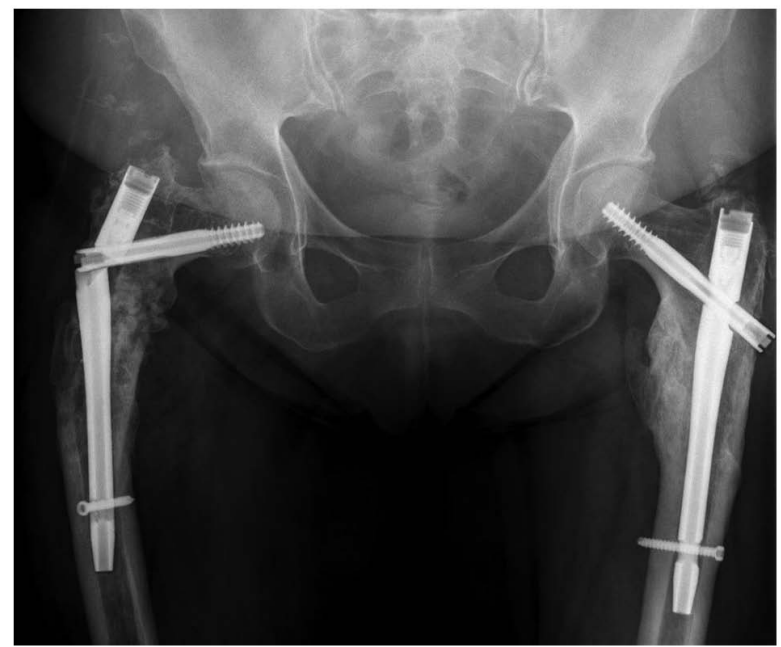

Figure 4. Approximately 6 months after right hip second surgery. Bone tunnel from the previous DCS screw is noticeable.

same method, but this time the nail broke after 6 months. The screw position was optimal. The insufficient restore of lateral femoral cortical bone was identified as the cause. The stress shielding forces were high and the bone healing was incomplete. The nail broke in the proximal part. A good solution was bone grafting and a longer nail. The same screw position was used the second time. Pain levels were low and the patient was able to walk. No follow-up was possible (Figs. 3 and 4). No sign of infection was identified. There were no skin complications and the bacterial cultures were negative.

An 83 years old patient, female, with diabetes, represents the third part of this report. She presented at the emergency room with pain. Weight bearing was impossible. She had a pertrochanteric fracture operated a year before in another service. The implant was compromised with no signs of callus. Blood sugar levels were uncontrolled and at the clinical exam, we identified multiple sacral sores. Clinical signs of shoulder arthritis were present. The affected thigh was $12 \mathrm{~cm}$ larger in diameter, hot and associated with redness. We decided to perform surgery and drainage. The following day, the patient was in a semicomatose state. During surgery, an extremely large quantity of pus was extracted.

During the same night, the patient went into septic shock with high potassium levels and anuria. She was unresponsive to norepinephrine and epinephrine. Death was recorded in the same night. Slow evolving sepsis, associated with comorbidities and a failed implant, all collaborated to the occurrence of the septic shock.

The proximal part of the broken nail was sent for analysis. Metallurgic tests and scanning with an electronic microscope were performed. Fatigue zones were identified at the contact between the nail and the screw. It is well-known that most of the fatigue cracks initiate at free surface. This phenomenon occurs only in special cases when a very high cycles fatigue test is performed (Fig. 5A and B) (16).

This type of changes in the structure were not confirmed at low-cycle or high-cycle fatigue tests for TIAl6V4 (17). We suspected that nonunion of the fracture was not the only cause of breakage. High tolerances of the lag screw guide (from 


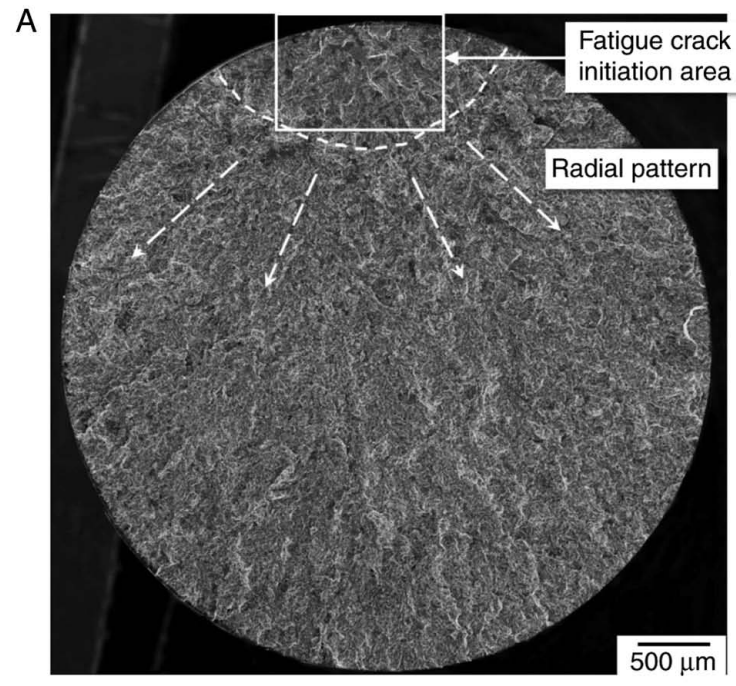

B

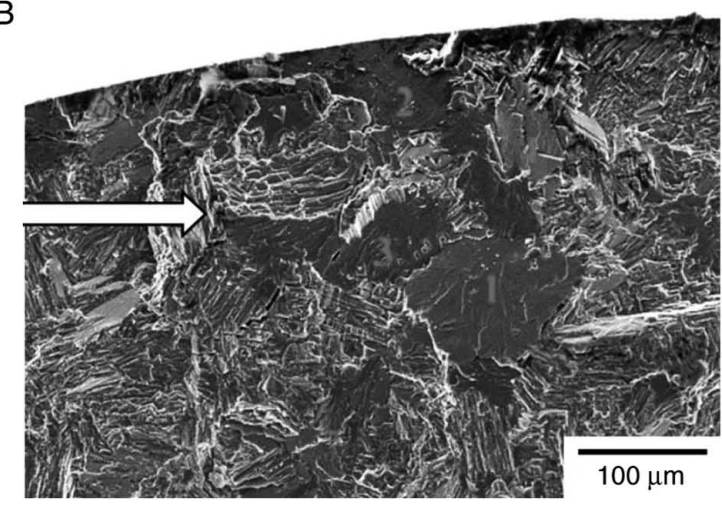

Figure 5. (A) Fatigue crack (modified). (B) Fatigue cracks initiation area (modified)-low stress. 1-4-titanium material crack initiation.

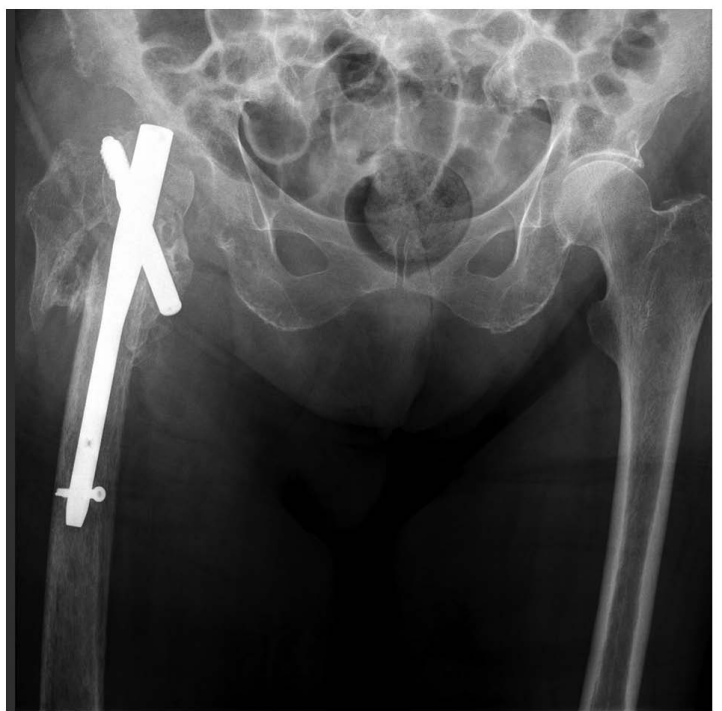

Figure 6. Eighty-three-year old patient, operated in another hospital, presented at our emergency room with local sepsis signs and major misplacement of the implant.

multiple uses) led to small errors in the screw placement. Small dents were seen under microscope at the beginning of

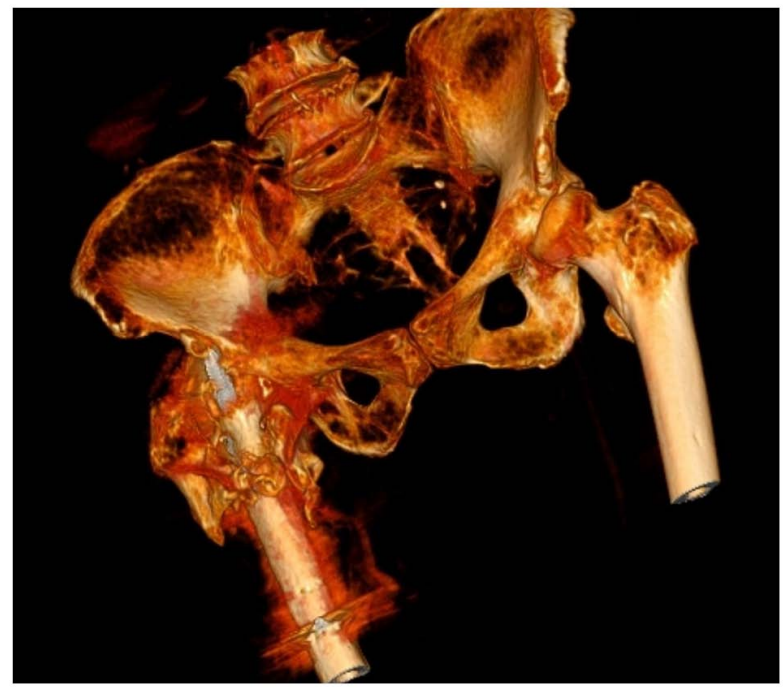

Figure 7.3D CT reconstruction of the 83-year old patient.

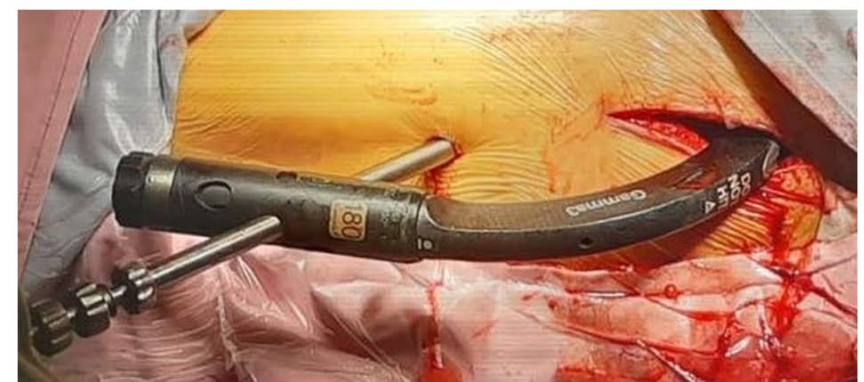

Figure 8. Nail guiding system.

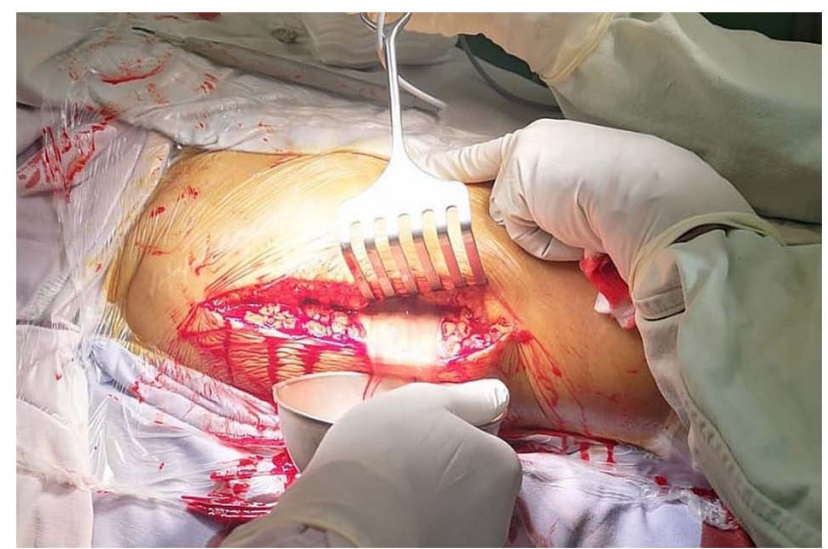

Figure 9. High quantity of pus in the hip region.

the primary fissure. The rigidity of the implant (titanium alloy) may eliminate micro-motions in the axial plane at the fracture site (producing delayed healing), causing extra load relative to the femur, that further causes stress shielding. Our theory is also confirmed by other articles. It took over 6 month for the nail to break. We found an average duration until failure of over 10 months in most studies (18-20).

Checking the guide for the lag screw, we identified an average of $1.4 \mathrm{~mm}$ error, from 10 tests. The cause for this 
error was the locking hex screw that locks the guide to the nail and also the threaded kirschner wire, used as a guide. That allows small errors at the passing of the drill through the nail. Small scratches on the coating and inside the nail's hole were observed.

The last case was an extremely misplaced implant with associated severe sepsis and non-union (Figs. 6 and 7). In this particular case, there was a drastic error in the reduction of the fracture, associated with life threatening comorbidities.

\section{Discussion}

The number of patients with peritrochanteric fractures is increasing, most likely due to the increase of average life span. Considering the gravity of this traumatic event, it is important to determine the factors that contribute and are associated with the failure of implant fixation. We tried to approach this subject from a different point of view. We focused on some particular cases that could lead us to some new presumption of why these systems sometimes fail. There are few publications on this topic and sometimes data are incomplete.

Peritrochanteric fractures represent a major issue of public health, as they are responsible for morbidity, increased mortality and high costs. Usually, after this type of surgery, the rehabilitation period is very long.

There is a constant debate about fast rehabilitation associated with weight bearing, as well as non-weight bearing protocols. Could this be the primary factor of gamma nail system fail? Osteoporosis has a prevalence of $\sim 10 \%$ in the USA. This number is considered very high, in an age were physical activity is decreasing and people's average life span is increasing (21). Most patients that were hospitalized with hip fractures are also suffering from osteoporosis or at least osteopenia. In the 23 patients with pre diagnosed osteoporosis and associated perthrocanteric fractures were included in our study, resulted from falls from ground level. We excluded lytic bone lesions as cause of these fractures. The two groups were divided randomly by the surgeon who performed the operations. In one group, there was a preference of very fast rehabilitation with weight bearing (FWB). We observed a very high cut-out rate for these small group (23\%). On the non-weight bearing group, only one case had a cut-out, but this incident was caused by lag screw misplacement.

Regarding BMI, there was no statistical correlation between these groups. The T-score was not relevant either. What we did note was that the weight bearing indication plays a crucial role in the outcome of the surgery. In osteoporotic patients, full weight bearing should be restricted to at least 6 weeks after surgery. Partial weight bearing can be allowed, but no more than $15 \%$ of the body weight. It is important to mention that this finding is relevant only to patients diagnosed with osteoporosis (22-24).

Based on our clinical experience, fast rehabilitation protocols associated with weight bearing decrease the recovery period after surgery, increase patient satisfaction, decrease the cost of the medical act and also augment the personal independence. According to our findings, this approach should be restricted to patients that have acceptable bone stock accompanied by an adequate surgical technique. Screw placement plays a crucial role in the outcome of this type of surgery (22).
One patient that we identified was a 61-year old woman, with a BMI of 29. She had been operated in our clinic after a failed DCS system (performed in another regional hospital), used for a peritrochanteric left hip fracture. The situation on the right leg was identical. We performed the second surgery, using a gamma nail fixation. After 6 months, the implant broke. We took into consideration inadequate reduction and insufficient restore of the lateral femoral wall as primary causes of failure. Consulting data from literature, we noted an average duration of over 10 months after nail breakage (18-20).

This finding led us to further investigate the broken implant, after extraction. On a microscopic view, we observed small cracks and dents produced by the lag screw in the hole of the nail. Titanium is an extremely stiff material, resilient to bending. It tends to increase stress shielding on fracture level. Small scratches in the weakest point of the nail can determine a decrease in resistance. In this particular case, this was the second surgery, so bone healing was slower. Could small errors in the guiding system cause a decrease of the nail resistance? We identified up to $1.4 \mathrm{~mm}$ of error in the system guiding instruments tray, caused by multiple use and perhaps also being inadequate (Fig. 8).

Several cases in literature have reported failed titanium or titanium alloy implants, specially gamma nails (19). Nonetheless, the overall long-term results for this type of material are still extremely good (25-30).

Most frequently, failure takes place as a result of high tensile stresses around notches, holes or small indentations. Exceeding the stress forces within the very thin $1.8-17 \mathrm{~nm}$ of protective coating (titanium oxide $\mathrm{TiO}_{2}$ ) can produce small/micro cracks followed by repassivation (31).

This effect is constant and is augmented by the corrosive environment (oxidative wear). Physiological loading induces unexpected, high cyclic stress during daily activity, weight bearing until fracture healing is complete. It is clear that none of these forces exceed the material's critical breaking point on one exposure, but it is a relevant issue after a high number of cycles. Microcracks in the material grow at a slow per-cycle velocity and can propagate to implant breakage until bone heals (32). The same principle of titanium alloy implants breakage was noticed in the modular systems. Due to small micromotions, the protective titanium oxide coating was destroyed and the implant failed due to increased fretting corrosion at the modular interface (33). In our case, the disruption of the titanium protective coating was iatrogenic. The drill for the lag-screw, due to small errors in the guiding system produces small scratches in the protective coating. The fracture site had a slow healing rate with high stress forces at this level. All led to a very fast implant breakage. It seems that this error severely decreased the implant's lifetime.

The next case that we analyzed was a failed gamma nail due to multiple causes. When including this case in the study, we wanted to advocate the fast reintervention for this type of patients. An 83-year old diabetic patient presented to our emergency room with clinical sepsis, with a malpositioned nail, without fracture reduction, 8 months after surgery in another hospital. She did not address another hospital services and no follow-up information was available during this period of time. Septic signs appeared one month before presenting to our clinic (family anamnesis, patient had a semicomatose 
status). At the clinical exam, we identified a right shoulder arthritis. Since the patient's status was rapidly declining, we decided to perform extraction of the implant and debridement (Fig. 9). Unfortunately, during surgery, the patient went into septic shock.

Failed gamma nails should be addressed rapidly. Peritrochanteric fractures increase morbidity and in conjunction with comorbidities can have a very high mortality rate. Septic complications can lead to sepsis or even shock. We analyzed this extreme case only to underline the fact that care must be exercised in fracture preoperative reduction and adequate nail and screw placement, since implant failing can sometimes lead to death.

Failure of gamma nail implants is not frequent, but still it must be avoided as much as possible. Such events lead to additional surgical procedures. In literature, the rate of breakage is reported in variable proportions; however, it is generally below $5.6 \%(19,34,35)$. There are many causes that may determine this complication.

The aim of this report was to identify lesser-known facts that can lead to surgical reintervention. According to our data, some patients have pre-existent osteoporosis. This comorbidity increases the percentage of implant failure. It is safe to say that full weight bearing should be allowed 6 weeks after or to patients that have good bone stock. Faster mobilization after surgery cannot always lead to good results, especially in old people with fragile bones. Lag screw placement and preoperative adequate fracture reduction are critical aspects that greatly influence the surgical outcome. A displaced implant associated with fractured delayed healing or cut-out should be addressed rapidly, since it can increase morbidity and sometimes lead to fatal complications.

In our study and after a thorough review of major publications, we have identified a novel factor of gamma nail failure. Breakage of the nail at the lag-screw level can be determined by errors in the guiding instruments. These high tolerances can cause dents or scratches in the protective titanium coating. This can lead to early implant breakage due to stress forces in a high-cycles environment. Extra care should be promoted to fracture reduction and adequate use of the gamma instruments tray. It is obvious that the forces exerted at this level do not meet the critical level of implant breaking point, but after a high number of cycles with a lower stress level, the lifetime and resistance of titanium alloy components are greatly reduced. This theory was also observed in other modular systems, used in the orthopedic field.

The gamma nail system remains one of the best solutions in the surgical treatment of pertrochanteric fractures, even though it may sometimes be associated with postoperative complications (36).

\section{Acknowledgements}

Professional editing, linguistic and technical assistance performed by Irina Radu, Individual Service Provider, certified translator in Medicine and Pharmacy (certificate credentials: Series E no. 0048).

\section{Funding}

No funding was received.

\section{Availability of data and materials}

All data generated or analyzed during this study are included in this published article.

\section{Authors' contributions}

SD planned the clinical study, performed the surgical procedures, contributed to the conception and design of the study, and the acquisition, analysis and interpretation of the data. CDMD contributed to the conception and design of the study, analysis of data, the drafting of the manuscript and its critical revision for important intellectual content. DCC contributed to the analysis and interpretation of the data and the critical revision for important intellectual content. CID and HTS contributed to the conception and design of the study and the critical revision of the manuscript for important intellectual content. CIS contributed to the conception and design of the study, the interpretation of the data and the critical revision of the manuscript for important intellectual content. All authors read and approved the final version of the manuscript and agreed to be accountable for all aspects of the study.

\section{Ethics approval and consent to participate}

The study was approved by the Ethics Committee of 'Foişor' Orthopedics-Traumatology and Osteoarticular TB Hospital (Bucharest, Romania). All patients provided a signed informed consent.

\section{Patient consent for publication}

Not applicable.

\section{Competing interests}

The authors declare that they have no competing interests.

\section{References}

1. White SM and Griffiths R: Projected incidence of proximal femoral fracture in England: A report from the NHS hip fracture anaesthesia network (HIPFAN). Injury 42: 1230-1233, 2011.

2. Gillespie WJ, Gillespie LD and Parker MJ: Hip protectors for preventing hip fracures in older people. Cochrane Database Syst Rev 6: CD001255, 2010.

3. Cameron ID, Kurrle SE, Quine S, Sambrook PN, March L, Chan DK, Locwood K, Cook B and Schaafsma FF: Improving adherence with the use of hip protectors among older people living in nursing care facilities: A cluster randomized trial. J Am Med Dir Assoc 12: 50-57, 2011.

4. Bjorgul K, Novicoff WM and Saleh KJ: Learning curves in hip fracture surgery. Int Orthop 35: 113-119, 2011.

5. Biber R, Gruninger S, Singler K, Sieber CC and Bail HJ: Is proximal femoral nailing a good procedure for teaching in orthogeriatrics? Arch Orthop Trauma Surg 132: 997-1002, 2012.

6. Loizou CL, McNamara I, Ahmed K, Pryor GA and Parker MJ: Classification of subtrochanteric femoral fractures. Injury 41 : 739-745, 2010.

7. Ramadier J, Duparc J, Rougemont D and De Ferrari G: Surgical treatment of trochanteric and juxta-trochanteric fractures. Rev Chir Orthop Reparatrice Appar Mot 42: 759-786, 1956 (In French).

8. Decoulx P and Lavarde G: Fractures of the trochanteric region. A statistical study of 2,612 cases. J Chir (Paris) 98: 75-100, 1969 (In French). 
9. Evans EM: The treatment of trochanteric fractures of the femur. J Bone Joint Surg Br 31B: 190-203, 1949.

10. Grigorie D, Sucaliuc A, Ciutan M and Vladescu C: Incidence and time trend of hip fractures in Romania: A nationwide study from 2008 to 2018. Acta Endocrinol (Buchar) 15: 505-512, 2019.

11. Mizrahi E, Fleissig Y, Arad M, Blumstein T and Adunsky A: Rehabilitation outcome of hip fracture patients: The importance of a positive albumin gain. Arch Gerontol Geriatr 47: 318-326, 2008.

12. Kuzyk PR, Zdero R, Shah S, Olsen M, Waddell JP and Schemitsch EH: Femoral head lag screw position for cephalomedullary nails: A biomechanical analysis. J Orthop Trauma 26 414-421, 2012.

13. Niinomi MJ: Mechanical biocompatibilities of titanium alloys for biomedical applications. J Mech Behav Biomed Mater 1: 30-42, 2008.

14. Elias CN, Lima JHC, Valiev R and Meyers MA: Biomedical applications of titanium and its alloys. JOM 60: 46-49, 2008.

15. Black J: Biologic performance of tantalum. Clin Mater 16 : 167-173, 1994.

16. Zuo JH, Wang ZG and Han EH: Effect of microstructure on ultra-high cycle fatigue behaviour of Ti-6Al-4V. Mater Sci Eng A 473: 147-152, 2008.

17. Wagner $\mathrm{L}$ and Lutjering G: Microstructural influences on propagation of short cracks in an $(\alpha+\beta)$ Ti-alloy. Z Metallkde 87: 369-375, 1987 (In German).

18. Willeumier JJ, Kaynak M, van der Zwaal P, Meylaerts SAG, Mathijssen NMC, Jutte PC, Tsagozis P, Wedin R, van de Sande MAJ, Fiocco M and Dijkstra PDS: What factors are associated with implant breakage and revision after intramedullary nailing for femoral metastases? Clin Orthop Relat Res 476: $1823-1833,2018$.

19. Iwakura T, Niikura T, Lee SY, Sakai Y, Nishida K, Kuroda R, and Kurosaka M: Breakage of a third generation gamma nail: A case report and review of the literature. Case Rep Orthop 2013: $172352,2013$.

20. Johnson NA, Uzoigwe C, Venkatesan M, Burgula V, Kulkarni A, Davison JN and Ashford RU: Risk factors for intramedullary nail breakage in proximal femoral fractures: A 10-year retrospective review. Ann R Coll Surg Engl 99: 145-150, 2017.

21. Wright NC, Looker AC, Saag KG, Curtis JR, Delzell ES, Randall S and Dawson-Hughes B: The recent prevalence of osteoporosis and low bone mass in the United States based on bone mineral density at the femoral neck or lumbar spine. J Bone Miner Res 29: 2520-2526, 2014.

22. Sharma V, Babhulkar S and Babhulkar S: Role of gamma nail in management of pertrochanteric fractures of femur. Indian J Orthop 42: 212-216, 2008.

23. Halder SC: The gamma nail for peritrochanteric fractures. J Bone Joint Surg Br 74: 340-344, 1992.
24. Kempf I, Grosse A, Taglang G and Favreul E: Gamma nail in the treatment of closed trochanteric fractures, results and indications apropos of 121 cases. Rev Chir Orthop Reparatrice Appar Mot 79: 29-40, 1993 (In French).

25. Busch CA, Charles MN, Haydon CM, Bourne RB, Rorabeck CH Macdonald SJ and McCalden RW: Fractures of distally-fixed femoral stems after revision arthroplasty. J Bone Joint Surg Br 87: 1333-1336, 2005.

26. Dangles CJ and Altstetter CJ: Failure of the modular neck in a total hip arthroplasty. J Arthroplasty 25: 1169.e5-e7, 2010.

27. Lakstein D, Eliaz N, Levi O, Backstein D, Kosashvili Y, Safir O and Gross AE: Fracture of cementless femoral stems at the mid-stem junction in modular revision hip arthroplasty systems. J Bone Joint Surg Am 93: 57-65, 2011

28. Magnissalis EA, Zinelis S, Karachalios T and Hartofilakidis G: Failure analysis of two Ti-alloy total hip arthroplasty femoral stems fractured in vivo. J Biomed Mater Res B Appl Biomater 66: 299-305, 2003.

29. Patel A, Bliss J, Calfee RP, Froehlich J and Limbird R: Modular femoral stem-sleeve junction failure after primary total hip arthroplasty. J Arthroplasty 24: 1143.e3-e5, 2009.

30. Sotereanos NG, Sauber TJ and Tupis TT: Modular femoral neck fracture after primary total hip arthroplasty. J Arthroplasty 28: 196.e7-e9, 2013.

31. Sul YT, Johansson CB, Petronis S, Krozer A, Jeong Y, Wennerberg A and Albrektsson T: Characteristics of the surface oxides on turned and electrochemically oxidized pure titanium implants up to dielectric breakdown: The oxide thickness, micropore configurations, surface roughness, crystal structure and chemical composition. Biomaterials 23: 491-501, 2002.

32. Ritchie RO, Davidson DL, Boyce BL, Campbell JP and Roder O High-cycle fatigue of Ti-6Al-4V. Fatigue Fract Engng Mater Struct 22: 621-631, 1999.

33. Gilbert JL, Buckley CA and Jacobs JJ: In vivo corrosion of modular hip prosthesis components in mixed and similar metal combinations. The effect of crevice, stress, motion, and alloy coupling. J Biomed Mater Res 27: 1533-1544, 1993.

34. Abram SG, Pollard TC and Andrade AJ: Inadequate 'three-point' proximal fixation predicts failure of the gamma nail. Bone Joint J 95-B: 825-830, 2013

35. Eberle S, Bauer C, Gerber C, von Oldenburg G and Augat P: The stability of a hip fracture determines the fatigue of an intramedullary nail. Proc Inst Mech Eng H 224: 577-584, 2010.

36. Liu M, Yang Z, Pei F, Huang F, Chen S and Xiang Z: A meta-analysis of the gamma nail and dynamic hip screw in treating peritrochanteric fractures. Int Orthop 34: 323-328, 2010.

(i) $\Theta$ This work is licensed under a Creative Commons

Attribution-NonCommercial-NoDerivatives 4.0 International (CC BY-NC-ND 4.0) License. 